\title{
Quantitative Assessment of the Chemical Safety of Groundwater Wells in Two Selected Districts of Rwanda
}

\author{
Wondatir Nigatu $^{1,}$ *, Chantal Andutirabose Umuhire ${ }^{2}$, Joseph Nsengimana ${ }^{1}$, Antoine Nsabimana ${ }^{3}$, \\ Sebashongore Dieudonne ${ }^{3}$
}

${ }^{1}$ Biology Department, University of Rwanda, College of Science and Technology, Kigali, Rwanda

${ }^{2}$ University of Rwanda, College of Science and Technology, Kigali, Rwanda

${ }^{3}$ Faculty of Science, University of Rwanda, College of Science and Technology, Kigali, Rwanda

\section{Email address:}

wnigatu1891@yahoo.co.uk (W. Nigatu), andutirabosechantal@yahoo.fr (C. A. Umuhire), josephnsengimana@yahoo.fr (J. Nsengimana), nsabimanant@yahoo.fr (A. Nsabimana), sebash_dieudonne@yahoo.fr (S. Dieudonne)

\section{To cite this article:}

Wondatir Nigatu, Chantal Andutirabose Umuhire, Joseph Nsengimana, Antoine Nsabimana, Sebashongore Dieudonne. Quantitative Assessment of the Chemical Safety of Groundwater Wells in Two Selected Districts of Rwanda. International Journal of Environmental Protection and Policy. Vol. 3, No. 4, 2015, pp. 104-110. doi: 10.11648/j.jjepp.20150304.14

\begin{abstract}
This research was conducted on groundwater wells of Bugesera and Muhanga districts in Rwanda where its physico-chemical parameters were determined as main aim. The study period was between February and May, 2015. A total of 18 water samples were collected from 12 sites. The laboratory experiment focused on the following quantitative determination parameters: Turbidity, pH, Temperature, Electrical Conductivity (EC), Total Dissolved Solids (TDS), Iron, Zinc, Manganese, Nitrate, and Phosphate. Alkalinities (range from 153 to $224 \mathrm{mg} / \mathrm{l}$ ) in all studied wells were above the standard. Except in one well above the standard, Zinc was detected below the standard in all wells $(0.01$ up to $0.3 \mathrm{mg} / \mathrm{l})$. Except one well below the range, Iron was found within the normal range in all wells $(0.005-1.00 \mathrm{mg} / \mathrm{l})$. Manganese was within the normal range in five wells of Bugesera district $(0.122-0.420 \mathrm{mg} / \mathrm{l})$, whereas below the WHO standard in all wells of Muhanga district $(0.003-$ $0.087 \mathrm{mg} / \mathrm{l})$. Except one well in Bugesera district all heavy metals in all wells were not exceeded the permissible limits. The samples from Kanogo groundwater well were containing a very high amount of Zinc and Manganese. In some wells detection were found below the standard. TDS (range from 70.5 to $232 \mathrm{mg} / \mathrm{L}$ ), $\mathrm{p}^{\mathrm{H}}$ (range from5.5 to 6.3) and Electrical conductivity (range from 128 to $335 \mu \mathrm{s} / \mathrm{cm}$ ) values in all studied wells were lower than standards provided by Rwanda Bureau of Standards (RBS) and World Health Organization (WHO). This study provides an insight on the quantitative measurements of some chemicals which do have relevance in the use of groundwater wells for domestic consumption. The wells can be utilized with proper management and regular monitoring. However, due to the high amount of heavy metal pollutants in the Kanogo groundwater well of Bugesera district this well should be monitored and treated for the moment. The government and other stakeholders together with the community should seek an alternative safe water supply source. Some preventive measures like planting trees around the well to protect it against entry discharge of residual waste and periodically cleaning of the wells are suggested. It is also important to sensitizing the community so that they can take precautionary measures to the cause; extent and impact of the contamination by these chemicals.
\end{abstract}

Keywords: Chemical Safety, Groundwater Wells, Bugesera and Muhanga Districts, Rwanda Bureau of Standards (RBS), World Health Organization (WHO) Standards

\section{Introduction}

Safe water supply for domestic use in developing countries needs to be a priority for the people. Despite significant efforts are made by different stakeholders for safe water supply still a large majority of the population do not have access for safe water source. At present, groundwater is the world's most extracted raw material with global withdrawal rates of $982 \mathrm{~km} 3$ /year [1]. More than half of the groundwater withdrawn is for domestic water supplies and globally it provides $25 \%$ to $40 \%$ of the world's drinking water [2]. Estimates made in 2010 shows that $30 \%$ of the global population obtaining drinking water from boreholes and dug wells $[2,3]$. Its quality is much affected by the activities 
occurring on the surrounding area of the water source. Groundwater pollution by the introduction of different pollutants (contaminants) into groundwater make the groundwater unclean and unsafe for drinking as well as unsuitable for different other purposes. The sources of groundwater pollution are usually classified by its origin and the four most common types of groundwater pollution include municipal, agricultural, industrial and individual groundwater pollution [4, 5]. Some groundwater pollution occurs naturally which is the case with arsenic commonly found in the sediments of the rock [4-6]. Cleaning groundwater pollution is very costly, in the most severe cases aquifer can be contaminated up to such level that it needs to be abandoned, meaning that the community must find a completely new supply of water which is extremely difficult and costs a lot of money. Adequate data on the accurate estimation of the exact type of groundwater pollution sources is very essential for cleaning efforts.

Water supply and sanitation in Rwanda is characterized by a rapid increase in access over the past years in rural areas, aided by a clear government policy and significant donor support [7]. In the country groundwater is one of the main water sources in addition to streams and rivers. $32 \%$ of Rwandans use piped water whereas the majority of the population depends on other sources [8]. According to the 2010 National Policy and Strategy for Water Supply and Sanitation Services the country set an ambitious plan in water supply and sanitation, with the vision to attain $100 \%$ service coverage by 2020, from surface water, springs and groundwater [8]. The Water and Sanitation Corporation (WASAC) of Rwanda has increase an effort to supply safe water in rural areas with access to safe water coverage of $74.5 \%$ in 2014 . However, the majority of the rural population has not clean water supply since the $40 \%$ of the constructed water facilities are not functioning due to the lack of proper operation and maintenance as well as other technical problems [9].

Water pollution can endanger people's health. Hence, it's better to do a study to clarify the quality of water from groundwater in order to increase the awareness of neighboring people on the use of unsanitary water source. In line to these all facts, this study was carried out to investigate the pollution caused as the result of some chemicals in groundwater wells supplies found in two selected districts of Rwanda by employing quantitative measurement. The results were compared with the Rwanda Bureau of Standards and WHO standards for such pollutants [5, 10-12].

\section{Materials and Methods}

\subsection{Study Area}

Rwanda map consists of five provinces [13]. Two provinces which are South and East provinces were randomly selected by a 'lottery system' from the five provinces (East, South, Kigali, Western and North provinces). From those two provinces two districts (one district from each province) which are Bugesera and Muhanga districts were also randomly selected. From these two districts, 12 sites of groundwater wells were selected, i.e., six sites in each district have been studied.

\subsection{Study Design and Sample Size}

The study design followed and sample size determined for this study was best summarized in Table 1 . The total number samples collected were 18 from 12 different sites of groundwater wells.

Table 1. Study design and sample size.

\begin{tabular}{lllll}
\hline Province & District & Sector & Sites of ground water wells & No. of samples collected \\
\hline \multirow{2}{*}{ South } & \multirow{2}{*}{ Muhanga } & Shyogwe & Safari, Kabeza and Byerwa & 3 \\
& & Nyamabuye & Merani, Nyarucyamu-1 and Nyarucyamu-2 & 3 \\
East & \multirow{2}{*}{ Bugesera } & Nyarugenge & Nyakabingo, Kadogori and Rwakiromba & 6 \\
& Ruhuha & Gatare1, Gatare 2 and Kanogo & 6 \\
\hline
\end{tabular}

\subsection{Sample Collection}

The samples were collected aseptically at the wells where most people fetch water. The sampling was done two times from six different sites (wells) in Bugesera and once from six different wells in Muhanga districts by using clean plastic bottles. Those bottles were washed with distilled water and dried before water sample collection in order to prevent cross contamination during collection.

\section{Analytical Procedures}

\subsection{Determination of Temperature and $p^{H}$}

The temperature and $\mathrm{p}^{\mathrm{H}}$ were measured by immersing the $\mathrm{p}^{\mathrm{H}}$ meter electrode in a water sample and results in ${ }^{0} \mathrm{c}$ were recorded for temperature and number without unit indicated the $\mathrm{p}^{\mathrm{H}}$. For such purpose the equipment S 20 Seven Easy ${ }^{\mathrm{TM}}$ pH-meter, supplied by METTLER TOLEDO Company, was used.

\subsection{Determination of Turbidity}

Turbidity was measured by using a turbid-meter (Turbidity Benchtop Meter, supplied by HANNA Instruments Company) in which the sample were placed and calibrated with turbidity standards, and then the value in NTU was recorded.

\subsection{Determination of Total Dissolved Solid (TDS) and Electrical Conductivity (EC)}

The total dissolved solid and electrical conductivity were measured by a unique instrument (conduct-meter, Model 
DDS-304 Conductivity-meter, supplied by HANNA Instruments Company) by immersing electrodes in the water sample after its calibration, then the values in $\mathrm{mg} / \mathrm{l}$ and $\mu \mathrm{s} / \mathrm{cm}$ for total dissolved solid and electrical conductivity were recorded respectively.

\subsection{Determination of Alkalinity}

Alkalinity was estimated titrimetrically where sulfuric acid $\left(0.02 \mathrm{~N} \mathrm{H}_{2} \mathrm{SO}_{4}\right)$ filled in burette was added slowly in water sample until the end point was reached (the phenolphthalein color changed to colorless) and the concentration of sulfuric acid added correspond to that of alkalinity present in the water sample. It was calculated as follow:

Alkalinity $\left(\mathrm{mg} / \mathrm{l} \mathrm{CaCO}_{3}\right)=[\mathrm{V} * \mathrm{~N} * 1000 / \mathrm{ml}$ sample $] * 100$

Where, $\mathrm{V}=$ Volume of the titrant and $\mathrm{N}=$ Normality of the titrant

\subsection{Nutrients}

The nutrients determined during this experiment were phosphates and nitrates.

\subsubsection{Determination of Phosphate $\left(\mathrm{PO}_{4}{ }^{3-}\right)$}

To the $25 \mathrm{ml}$ of the water samples, $1.00 \mathrm{ml}$ of ammonium molybdate solution $\left((\mathrm{NH} 4)_{6} \mathrm{Mo}_{7} \mathrm{O}_{24} \bullet 4 \mathrm{H}_{2} \mathrm{O}\right)$ was added into the flask and mixed. To the flask, 2 drops of stannous chloride solution $\left(\mathrm{SnCl}_{2} \cdot 2 \mathrm{H}_{2} \mathrm{O}\right)$ was added and mixed by swirling. A blue color was developed if phosphates were present to a maximum in 5 minutes. Absorbance was measured at $650 \mathrm{~nm}$ using a spectrophotometer (DR $5000^{\mathrm{TM}}$ U.V Spectrophotometer, supplied by HACH Company). The results were compared with a calibration curve using distilled water as blank and known phosphate standards treated through the same procedure used for the sample. The sample containing high phosphate concentration is with blue color.

\subsubsection{Determination of Nitrate $\left(\mathrm{NO}_{3}^{-}\right)$}

Nitrate was determined indirectly by conversion of nitrite into nitrate. First, nitrite solution was prepared by adding nitrite reagent into $10 \mathrm{ml}$ of each water sample and the concentration of the prepared solution was measured using a UV spectrophotometer instrument (DR $5000^{\mathrm{TM}}$ U.V Spectrophotometer, supplied by $\mathrm{HACH}$ Company). The conversion factor of 3.28 was used to convert nitrite $\left(\mathrm{NO}_{2}^{-}\right.$ $\mathrm{mg} / \mathrm{l})$ into total nitrogen $(\mathrm{N} \mathrm{mg} / \mathrm{l})$ and 4.43 were used to convert total nitrogen into nitrate $\left(\mathrm{NO}_{3}{ }^{-} \mathrm{mg} / \mathrm{l}\right)$.

\subsubsection{Determination of Heavy Metals}

Heavy metals (iron, manganese and zinc) and nutrients were determined by Atomic Absorption Spectrophotometer (DR $5000^{\mathrm{TM}}$ U.V Spectrophotometer, supplied by $\mathrm{HACH}$ Company).

\subsection{Data Analysis}

Data records were summarized systematically in a form of tables after determination of the different physico-chemical tests.

\section{Results}

\subsection{Physical Test Results}

The physical test results obtained from this investigation are summarized in Table 2 and Table 3.

Table 2. Results of physical parameters for Bugesera samples.

\begin{tabular}{|c|c|c|c|c|c|c|c|c|c|c|c|c|c|}
\hline \multirow{2}{*}{ Test } & \multicolumn{2}{|l|}{ S I } & \multicolumn{2}{|l|}{ S II } & \multicolumn{2}{|l|}{ S III } & \multicolumn{2}{|l|}{ S IV } & \multicolumn{2}{|l|}{$\mathbf{S ~ V}$} & \multicolumn{2}{|l|}{ S VI } & \multirow{2}{*}{$\begin{array}{l}\text { WHO } \\
\text { Standards }^{[5,12}\end{array}$} \\
\hline & R1 & $\mathbf{R 2}$ & R1 & $\mathbf{R 2}$ & R1 & R2 & R2 & R1 & R2 & R1 & R1 & R2 & \\
\hline $\mathrm{p}^{\mathrm{H}}$ & 5.6 & 5.5 & 5.7 & 5.7 & 5.6 & 5.6 & 5.7 & 5.5 & 6.3 & 6.1 & 5.6 & 5.5 & $6.5-8.5$ \\
\hline $\mathrm{T}\left({ }^{0} \mathrm{C}\right)$ & 26.4 & 25.2 & 26.1 & 24.8 & 26.2 & 25.8 & 25.9 & 24 & 26 & 25.5 & 25 & 24.6 & $20-40$ \\
\hline $\mathrm{Ec}(\mu \mathrm{s} / \mathrm{cm})$ & 218 & 222 & 306 & 318 & 128 & 150 & 165 & 183 & 320 & 335 & 254 & 282 & $400-1300$ \\
\hline Turb. (NTU) & 2.3 & 2.5 & 2.8 & 3.0 & 2.05 & 2.4 & 2.2 & 2.8 & 4.0 & 4.5 & 3.2 & 3.5 & $<5$ \\
\hline TDS (mg/l) & 119 & 153 & 168 & 182 & 70.5 & 73 & 90.3 & 94 & 176 & 195 & 140 & 172 & $500-1000$ \\
\hline $\operatorname{Alk}(\mathrm{mg} / \mathrm{l})$ & 192 & 153 & 176 & 180 & 184 & 191 & 200 & 163 & 176 & 204 & 224 & 198 & 120 \\
\hline
\end{tabular}

Legend: R1\&R2: Round one and round two; SI=Rwakiromba, SII=Kadogori, SIII=Gatare 1, SIV=Gatare 2, SV=Nyakabingo and SVI=Kanogo groundwater wells

Table 3. Physical test results of Muhanga water samples.

\begin{tabular}{llllllll}
\hline Param/test & S I & S II & S III & S IV & S V & S VI & WHO standards $^{[5,12]}$ \\
\hline $\mathrm{P}^{\mathrm{H}}$ & 6.33 & 5.61 & 6.00 & 5.8 & 5.70 & 6.18 & $6.5-8.5$ \\
$\mathrm{~T}\left({ }^{0} \mathrm{C}\right)$ & 25.8 & 25.4 & 26.0 & 25.5 & 25.2 & 26.4 & $20-40$ \\
$\mathrm{Ec}(\mu \mathrm{s} / \mathrm{cm})$ & 235 & 137 & 214 & 302 & 170 & 288 & $400-1300$ \\
Turb. $(\mathrm{NTU})$ & 3.02 & 2.04 & 2.15 & 3.22 & 2.09 & 2.55 & $<5$ \\
$\mathrm{TDS}(\mathrm{mg} / \mathrm{l})$ & 232 & 180 & 195 & 95.8 & 164 & 151 & $500-1000$ \\
Alk. $(\mathrm{mg} / \mathrm{l})$ & 200 & 184 & 175 & 193 & 220 & 188 & 120 \\
\hline
\end{tabular}

Legend: SI=Merani, SII=Kabeza, SIII=Safari, SIV=Byerwa, SV=Nyarucyamu 1, SVI=Nyarucyamu 2 groundwater wells.

\subsection{1. $p^{H}$ Results}

$\mathrm{P}^{\mathrm{H}}$ is a term used generally to express the strength of the acid or alkaline condition of a solution. Most of the ground water $\mathrm{p}^{\mathrm{H}}$ was found slightly acidic. The $\mathrm{p}^{\mathrm{H}}$ values obtained from the study areas were varied from 5.5 to 6.3 in Bugesera for both rounds and ranged from 5.70 to 6.33 in Muhanga. 


\subsubsection{Temperature Results}

The temperature was slowly increasing from the first to the second round because of rainfall that decreased the ambient temperature. The recorded temperatures of the analyzed samples were in the range of 25.2 to $26.4^{\circ} \mathrm{C}$ for Bugesera and range from 25.2 to $26.4^{\circ} \mathrm{C}$ in Muhanga.

\subsubsection{Electrical Conductivity Test Results}

Electrical conductivity (EC) is a measure of water capacity to transport electric current and it indicates the amount of total dissolved salts. Electrical conductivity values at Bugesera wells range between 128 to $335 \mu \mathrm{s} / \mathrm{cm}$ and range from 170 to $302 \mu \mathrm{s} / \mathrm{cm}$ in Muhanga.

\subsubsection{Turbidity Test Results}

The degree of turbidity in water is often taken to be an appropriate measure of the intensity of pollution. The turbidity in the study area varied between 2.05 to $4.05 \mathrm{NTU}$ in Bugesera and range from 2.04 to 3.22 NTU in Muhanga.

\subsubsection{Total Dissolved Solid Test Results}

Total Dissolved Solid (TDS) was used as indicators of aesthetic characteristic and salinity behavior of ground water. The TDS values found from Bugesera water samples during the experiment range from 70.51 to $195 \mathrm{mg} / \mathrm{l}$ and range from 95.8 to $232 \mathrm{mg} / \mathrm{l}$ in Muhanga.

\subsubsection{Alkalinity Test Results}

Alkalinity of water is its capacity to neutralize a strong acid and it is normally due to the presence of bicarbonate, carbonate and hydroxide compound of calcium, sodium and potassium. Natural waters that contain $40 \mathrm{mg} / \mathrm{CaCO}_{3}$ or more total alkalinity are considered as hard water. In this experiment the measured alkalinity results range from 153 to $224 \mathrm{mg} / \mathrm{l}$ for Bugesera and from 175 to $220 \mathrm{mg} / \mathrm{l}$ in Muhanga.

\subsection{Nutrients and Heavy Metals}

Results for nutrients and heavy metals are presented in Table 4 and Table 5.

Table 4. Results for nutrients \& heavy metals obtained from Bugesera samples.

\begin{tabular}{|c|c|c|c|c|c|c|c|c|}
\hline Param/test & & S I & S II & S III & S IV & $\mathbf{S ~ V}$ & S VI & WHO standards ${ }^{[5,12]}$ \\
\hline \multirow{2}{*}{$\mathrm{NO}_{3}^{-}(\mathrm{mg} / \mathrm{l})$} & RI & 2.2 & 4.2 & 1.8 & 3.2 & 2.1 & 3.5 & $1-50$ \\
\hline & RII & 2.5 & 3.9 & 2.2 & 3.3 & 1.8 & 3.2 & $1-50$ \\
\hline \multirow{2}{*}{$\mathrm{PO}_{4}{ }^{2-}(\mathrm{mg} / \mathrm{l})$} & RI & 0.17 & 0.42 & 0.17 & 0.18 & 0.21 & 0.64 & $0-5$ \\
\hline & RII & 0.19 & 0.38 & 0.16 & 0.22 & 0.25 & 0.58 & $0-5$ \\
\hline \multirow{2}{*}{$\mathrm{Fe}(\mathrm{mg} / \mathrm{l})$} & RI & 0.02 & 0.04 & 0.1 & 0.05 & 0.004 & 0.08 & $0.01-3$ \\
\hline & RII & 0.05 & 0.08 & 0.3 & 0.09 & 0.005 & 0.1 & $0.01-3$ \\
\hline $\mathrm{Zn}(\mathrm{mg} / \mathrm{l})$ & RII & 0.05 & 0.03 & 0.1 & 0.06 & 0.08 & undetectable & $1-2$ \\
\hline \multirow{2}{*}{$\mathrm{Mn}(\mathrm{mg} / \mathrm{l})$} & RI & 0.212 & 0.201 & 0.122 & 0.315 & 0.385 & undetectable & $0.1-0.8$ \\
\hline & RII & 0.251 & 0.189 & 0.153 & 0.298 & 0.420 & undetectable & $0.1-0.8$ \\
\hline
\end{tabular}

Legend: RI\&RII: Round one and round two; SI=Rwakiromba, SII=Kadogori, SIII=Gatare1, SIV=Gatare2, SV=Nyakabingo and SVI=Kanogo groundwater wells.

Table 5. Nutrients \& heavy metals results for Muhanga samples.

\begin{tabular}{llllllll}
\hline Param/test & S I & S II & S III & S IV & S V & S VI & WHO standards ${ }^{[5,12]}$ \\
\hline $\mathrm{NO}_{3}{ }^{-}(\mathrm{mg} / \mathrm{l})$ & 2.5 & 4.0 & 3.2 & 4.5 & 1.7 & 2.2 & 0.49 \\
$\mathrm{PO}_{4}{ }^{-2}(\mathrm{mg} / \mathrm{l})$ & 0.23 & 0.15 & 0.44 & 0.52 & 0.65 & $0-5$ \\
$\mathrm{Iron}(\mathrm{Fe})(\mathrm{mg} / \mathrm{l})$ & 0.67 & 0.45 & 1.00 & 0.83 & 0.52 & 0.92 \\
Zinc(Zn) $(\mathrm{mg} / \mathrm{l})$ & 0.02 & 0.09 & 0.5 & 0.3 & 0.04 & 0.15 \\
Manganese (mg/l) & 0.005 & 0.087 & 0.003 & 0.007 & 0.037 & 0.009 \\
\hline
\end{tabular}

Legend: SI=Merani, SII=Kabeza, SIII=Safari, SIV=Byerwa, SV=Nyarucyamu 1, SVI=Nyarucyamu 2 groundwater wells

\subsubsection{Nitrate Results}

Groundwater contains nitrate due to the leaching of soil from fertilized fields and manures from the land. This was the fact that, the agriculture activities which take place around the well contributes to the increase of nitrates concentration from fertilizers which is mainly NPK (Nitrogen-Phosphorus-Potassium). The nitrate values for Bugesera study range from 1.8 to $4.2 \mathrm{mg} / \mathrm{l}$ and from 0.15 to $0.65 \mathrm{mg} / 1$ in Muhanga.

\subsubsection{Phosphate Results}

The phosphate is of greater importance as an essential nutrient in aquatic system and may occur in groundwater as a result of domestic sewage, detergents and agricultural effluents with fertilizers. The phosphate content in the study area was found between $0.16 \mathrm{mg} / \mathrm{L}$ and $0.64 \mathrm{mg} / \mathrm{l}$ in Bugesera and between 0.15 and $0.65 \mathrm{mg} / \mathrm{l}$ in Muhanga.

\subsubsection{Iron Results}

Iron ranged from $0.02 \mathrm{mg} / \mathrm{l}$ to $0.3 \mathrm{mg} / \mathrm{l}$ in Bugesera collected water samples for both rounds and range from 0.45 to $1.00 \mathrm{mg} / \mathrm{l}$ for Muhanga collected samples.

\subsubsection{Zinc Results}

For both rounds, in Bugesera, the values of zinc were almost the same for each sample, but the last sample was containing a very high amount of zinc in such a way it was 
found undetectable and in Muhanga the results of Zinc test range from 0.02 to $0.15 \mathrm{mg} / 1$.

\subsubsection{Manganese Results}

The concentration of manganese was within the normal range in the first five wells of Bugesera district $(0.122-$ $0.420 \mathrm{mg} / \mathrm{l})$, whereas below the WHO standard in all wells of Muhanga district $(0.003-0.087 \mathrm{mg} / \mathrm{l})$. The concentration of manganese was high in Bugesera above the WHO's standard in such way that for the last sample it was undetectable.

\section{Discussion}

\subsection{Physical Parameters}

\subsection{1. $\mathrm{pH}$}

Most of the ground water $\mathrm{p}^{\mathrm{H}}$ is slightly acid. The $\mathrm{p}^{\mathrm{H}}$ values obtained in the study areas vary from 5.5 to 6.3 in Bugesera for both rounds. As showed in Table 2 and Table 3 the $\mathrm{p}^{\mathrm{H}}$ values were increasing from the first round to the second round. This could be of the reason that the activities along those wells are able of adding more acids. The $\mathrm{p}^{\mathrm{H}}$ results of Bugesera water wells were low compared to $\mathrm{p}^{\mathrm{H}}$ of water from Muhanga. But both $\mathrm{p}^{\mathrm{H}}$ values of Bugesera and Muhanga wells were found below the $\mathrm{p}^{\mathrm{H}}$ range prescribed by RBS for drinking water which range from 6.5 up to $8.5[10,11]$. So, this parameter may cause any harmful effect to human health. Low water $\mathrm{pH}$ will cause redness and irritation to eyes below a $\mathrm{pH}$ of 4 . And while a water $\mathrm{pH}$ of 2.5 or lower is uncommon, exposure to water of this acidity will cause extensive and irreversible damage to the skin cells that detect sensation [14].

\subsubsection{Temperature}

The temperature was slowly increasing from the first to the second round because of rainfall that decreased the ambient temperature in Bugesera as the second round sampling was done during the raining season. Muhanga results in temperature didn't show great difference among them and also with the temperature of the first round of Bugesera because of their samplings were carried out within the same period. But the temperature for all sites is normal when compared to the WHO's drinking water standard values (20$40^{\circ} \mathrm{C}$ ) by then may not have a harmful effect to the human health and the surrounding environment.

\subsubsection{Electrical Conductivity}

Electrical conductivity values at Bugesera wells varied increasingly from the first to the second round. No significant difference was found when comparing Bugesera and Muhanga values for electrical conductivity. Both Bugesera and Muhanga values were below the range of WHO standards guideline of drinking water $(400-1300 \mu \mathrm{s} / \mathrm{cm})$ where such groundwater is not safe. The variation in electrical conductivity in each site may indicate differences in pollution load and evaporative concentration of ion. Electrical conductivity value of drinking water contributes to disturbance of the salt and water balance in children [5].

\subsubsection{Turbidity}

The degree of turbidity in water is often taken to be an appropriate measure of the intensity of pollution. Turbidity increased for the second round in Bugesera and this may be occurred due to the direct discharge of soil from agricultural runoff, and other human activities like washing, bathing or the presence of large number of microorganisms. Bugesera obtained turbidity values were high compared to Muhanga obtained values. For both Bugesera and Muhanga, the turbidity was within the range of permissible values prescribed by WHO and RBS [5, 10-12] for safe drinking water quality $(<5 \mathrm{NTU})$, which mean it may not cause problem to human health.

\subsubsection{Total Dissolved Solid (TDS)}

The TDS values found from Bugesera water samples were increasing from the first to the second round during the experiment period. This occurred due to highly leaching of domestic waste and contaminated soil from agricultural activities compare to other sites. Compared to Muhanga TDS values, the Bugesera TDS values were low. But all TDS values obtained were below the range of WHO $(>500 \mathrm{mg} / \mathrm{l})$ and the RBS limits $(>700 \mathrm{mg} / \mathrm{l})$ of drinking water.

\subsubsection{Alkalinity}

Natural waters that contain $40 \mathrm{mg} / 1$ of $\mathrm{CaCO}_{3}$ or more the alkalinity are considered as hard water [5]. In our experiment the measured alkalinity results showed no great difference in variation in both Bugesera and Muhanga districts. The alkalinity level observed in all sites in the study areas exceeds the value $120 \mathrm{mg} / \mathrm{l}$ recommended by WHO standards for water quality and may have a negative impact to human health $[5,12]$. Alkalinity is important because it protects or buffers against rapid $\mathrm{p}^{\mathrm{H}}$ changes, high alkalinity for drinking water has some unknown systemic effects leading to growth retardation $[5,15]$.

\subsection{Nutrients and Heavy Metals}

\subsubsection{Phosphate}

The phosphate is of greater importance as an essential nutrient in aquatic system and may occur in groundwater as a result of domestic sewage, detergents and agricultural effluents with fertilizers [5]. Phosphate in both rounds for Bugesera and in Muhanga varied uniformly. However, the phosphate content in the whole study water samples were found in the range of the recommended standards of drinking water by Rwanda Bureau of Standards (0-2.2 mg/l) and WHO standards $(0-5 \mathrm{mg} / \mathrm{l})$.

\subsubsection{Nitrate}

Groundwater contains nitrate due to the leaching of soil from fertilized fields and manures from the land [5]. This was the fact that, the agriculture activities which take place around the well contributes to the increase of nitrates concentration from fertilizers which is mainly NPK (Nitrogen-Phosphorus-Potassium). The nitrate values for Bugesera and Muhanga study varied uniformly but all obtained results were in the range of the WHO's standards of 
drinking water (1-50 mg/l).

\subsubsection{Iron}

In Bugesera collected water samples for both rounds there was no great difference in results of iron content from the first to the second round. The decrease in iron at the sample $\mathrm{V}$ (Nyakabingo) may be due to the oxidation of iron by oxygen. For both Bugesera (except one) and Muhanga wells, results obtained from Iron test were within the range provided by WHO's drinking water standards $(0.01-3 \mathrm{mg} / \mathrm{l})$. However, the iron values for Muhanga water samples were high compared to those of Bugesera.

\subsubsection{Manganese}

In Bugesera, the concentration of manganese was within the limit of WHO's drinking water standards (0.1-0.8 mg/l) for both rounds in almost all wells. However, in one well it was found undetectable which means it is in high concentration. This may be accounted due to the soil of Kanogo in Bugesera is rich in manganese thereby water from this well would not be safe as drinking water. High amount of Manganese in drinking water has harmful effect on human health. Persons drinking such water will show neurological signs because Manganese in high amount leads to production of a neurotoxin [16]. Muhanga Manganese values were very low compared to those of Bugesera and they were in the range of WHO's drinking water standards.

\subsubsection{Zinc}

For both rounds, in Bugesera, the values of Zinc were almost the same for all samples, but the last showed great variation because its Zinc was undetectable which means the water from kanogo well is not good for drinking. In Muhanga all the collected water samples contains Zinc content within the WHO's drinking water standards and have no harmful effect on human health.

Zinc in the human body is an important characteristic. One may also absorb Zinc over doses through drinking water containing high Zinc concentration. Symptoms of effect of drinking water with high Zinc includes: nausea, vomiting, dizziness, fevers, diarrhea and acute toxicity leading to stomach aches. Other related health effects also include mucous membrane infection $[14,15,17]$.

\section{Conclusion}

This study had provided information about the water quality of Bugesera and Muhanga groundwater wells as indicated by its physico-chemical characteristics. The wells may receive pollutants from different anthropogenic activities carried out in its surrounding areas like farming, fishing, and improper disposal of solid waste which were transported through soil erosion and agriculture runoff [18]. Groundwater pollution may also occur naturally from arsenic pollutants commonly found in the sediments of the rock [4-6]. The presence of those pollutants in either way influences the water qualities which may harm the public health [19]. According to results obtained by the laboratory analysis of water samples from both Bugesera and Muhanga, it has been shown that some parameters are not in the acceptable range of Rwanda Bureau of Standards or WHO's water quality standards of drinking water like $\mathrm{p}^{\mathrm{H}}$, electrical conductivity, iron, and manganese which had high or low values. Those analyzed parameters confirmed that, some of the water wells studied in this investigation are chemically and physically polluted and are unfit for drinking purpose.

From this study it is recommended that 1) Due to the high amount of heavy metal pollutants in the Kanogo groundwater well of Bugesera district this well should be monitored and treated. The people utilizing the other studied wells need to avoid the use of that groundwater well in their daily life activities without any treatment, 2) The government and other partners may need to increase efforts in providing potable water in rural places, 3) The public need to be aware about the status of the well waters in relation to chemical safety, 4) Supplementary research is needed in order to evaluate other parameters such as Biological parameters and other heavy metals in order to have full knowledge of about the quality of groundwater wells, and 5) Grant the best management practices like planting trees around the well and this can prevent some of the nutrient residues from entering the well.

\section{Authors' Contributions}

The paper write up was undertaken by WN. CAU carried out laboratory experiments under $\mathrm{WN}$ supervision. JN, AN and SD contributed in commenting and facilitating necessary materials for the research work and manuscript preparation.

\section{Acknowledgements}

The authors would like to acknowledge individuals who contribute to this study directly or indirectly in which without their support it could not possible to be successful. The University of Rwanda-College of Science and Technology is acknowledged for making available some of the reagents used for chemical analysis. We also express our great thanks to technical staffs of Chemistry Department laboratory who facilitated and participated in this study.

\section{References}

[1] Margat, J., and J. van der Gun, "Groundwater around the World”, CRC Press/Balkema, 2013.

[2] National Groundwater Association, "Facts about Global Groundwater Usage”, 2015. http://www.ngwa.org/Fundamentals/use/Documents/globalgroundwater-use-fact-sheet.pdf, accessed on 09/06/2015.

[3] UNICEF, WHO, "Progress on Drinking Water and Sanitation", UNICEF, World Health Organization, 2012 Update, p. 10, 2012.

[4] http://pollutionarticles.blogspot.com/2011/11/groundwaterpollution-facts.html, accessed on 09/06/2015. 
[5] WHO, "Guidelines for drinking water quality", $4^{\text {th }}$ ed, Water quality standards, World Health Organization, Switzerland, 2011.

http://whqlibdoc.who.int/publications/2011/9789241548151_e ng.pdf?ua $=1$

[6] G.J. Alaerts, N. Khouri, B. Kabir, "Strategies to mitigate arsenic contamination of water supply", The World Bank, Washington, DC, USA, 2001. http://www.who.int/water_sanitation_health/dwq/arsenicun8.p df

[7] Ministry of Lands, Environment, Forests, Water and Mines (MINITERE), "Scaling up Investment and Reforms Through National Program and Performance Contracts", Emmanuel Nsanzumuganwa, February 2008

[8] Ministry of Infrastructure, "National Policy \& Strategy for Water Supply and Sanitation Services", Rwanda, February 2010 .

[9] WASAC, "Project for strengthening operation and maintenance of rural water supply systems in Rwanda." http://www.wasac.rw/

[10] RS2., "Potable water specification", $2^{\text {nd }}$ ed, Rwanda Bureau of Standard (RBS), Kigali, 2012.

[11] Gashugi Elisee, Uwikund Sylvie et.al., "Physico-chemical analysis of groundwater from Rugende II well, Rwamagana district, Rwanda". East African Journal of Science and Technology, vol 3, No 1, 104-111, 2013.

[12] WHO, "Guidelines for Drinking-water Quality", Geneva, 1993. http://www.lenntech.com/applications/drinking/standards/who -s-drinking-water-standards.htm

[13] Rwanda political map features the international boundary, the country boundaries with their capitals, national capital and other important cities. http://www.mapsofworld.com/rwanda/rwanda-politicalmap.html

[14] Merne ME1, S. K., "Systemic and local effects of long-term exposure to alkaline drinking water in rats". Int J Exp Pathol., 82(4), 213-9, 2001.

[15] Wei Bai, Linguei Kong, Aiguo Guo, "Effects of physical properties on electrical conductivity." Journal of Rock Mechanics \& Geotechnical Engineering,vol.5(5):406-411, October 2013.

[16] Bouchard M. and Sauve,S. et al., "Intellectual impairment in school-Age children Exposed to Manganese from drinking water", Environmental Health Perspectives, 2010. DOI:10./1289/ehp.1002321

[17] Goyer, R. A., "Toxic Effects of Metals." In Casarett \& Doull's Toxicology: Basic Science of Poisons, ed. C. D. Klaassen. New York: McGraw-Hill, 1996.

[18] Olapade OJ and BO Omitoyin, "Anthropogenic pollution impact on physico-chemical characteristics of Lake Kivu." African journal of food, agriculture, nutrition and development, Vol.12, 2012.

[19] M. J. Ellenhorn,D.G.Barceloux,"Medical toxicology: diagnosis and treatment of human poisoning", New York, Elsevier Science publishing company 1988. 